\title{
Sedentary lifestyle and precocious puberty in girls during the COVID-19 pandemic: an Italian experience
}

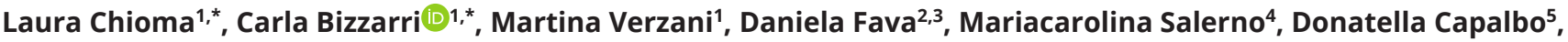 \\ Chiara Guzzetti ${ }^{6}$, Laura Penta7 ${ }^{7}$ Luigi Di Luigi ${ }^{8}$, Natascia di lorgi ${ }^{2,3}$, Mohamad Maghnie ${ }^{2,3}$, Sandro Loche ${ }^{\mathbb{6} 6}$ and \\ Marco Cappa ${ }^{1}$

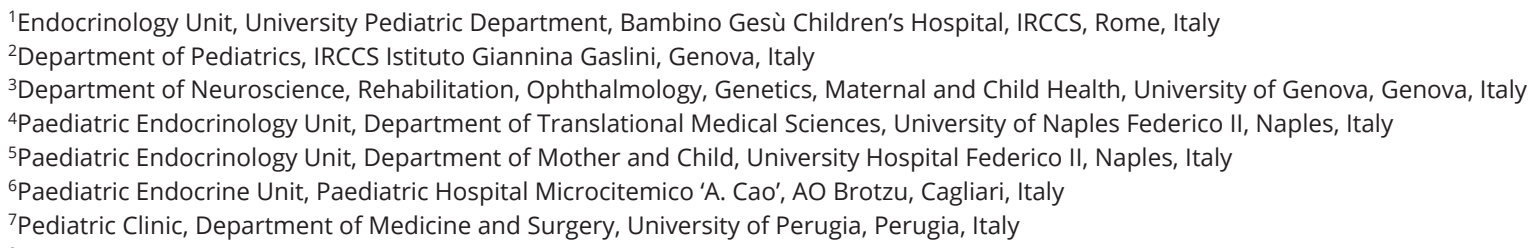

\begin{abstract}
Objective: This retrospective study aimed to evaluate children observed for suspected precocious puberty in five Italian centers of Pediatric Endocrinology during the first wave of coronavirus disease 2019 pandemic (March-September 2020), compared to subjects observed in the same period of the previous year.

Design: The study population (490 children) was divided according to the year of observation and final diagnosis: transient thelarche, non-progressive precocious puberty, central precocious puberty (CPP), or early puberty.

Results: Between March and September 2020, 338 subjects were referred for suspected precocious puberty, compared to 152 subjects in the same period of $2019(+122 \%)$. The increase was observed in girls (328 subjects in 2020 vs 140 in 2019, $P<0.05$ ), especially during the second half of the period considered ( 92 girls from March to May vs 236 girls from June to September); while no difference was observed in boys (10 subjects in 2020 vs 12 in 2019). The percentage of girls with confirmed CPP was higher in 2020, compared to 2019 (135/328 girls (41\%) vs $37 / 140(26 \%), P<0.01)$. Anthropometric and hormonal parameters in 2019 and 2020 CPP girls were not different; 2020 CPP girls showed more prolonged use of electronic devices and a more sedentary lifestyle both before and during the pandemic, compared to the rest of the 2020 population.

Conclusions: The present findings corroborate the recently reported association between the complex lifestyle changes related to the lockdown and a higher incidence of CPP in Italian girls.
\end{abstract}
Key Words
- precocious puberty
- COVID-19 pandemic
- lockdown
- physical exercise
- sedentary lifestyle

Endocrine Connections (2022) 11, e210650 


\section{Introduction}

Puberty represents an essential step of dynamic transition from childhood to adulthood leading to full reproductive capacity. The mechanisms underlying this process are not completely known and include genetic and epigenetic factors, as well as energy balance and variation in the expression of brain neurotransmitters and neuropeptides $(1,2,3,4)$.

A trend toward earlier puberty onset has been observed in the last decades $(5,6,7)$. It has been linked to changes in body weight and obesity $(8,9)$, exposure to environmental endocrine disruptors (10), and stressful life events (11). Recently, it has been proposed that precocious puberty may represent the expression of an adaptive mechanism to escape from ectopic adiposity in girls with low birth weight and significant postnatal weight gain $(12,13,14,15)$.

Precocious puberty is defined as the onset of thelarche before the age of 8 years in females and of testicular enlargement before 9 years in males, equivalent to 2 s.D. below the mean age at the onset of puberty (16).

At the end of 2019, a novel coronavirus identified as severe acute respiratory syndrome coronavirus 2 (SARS-CoV-2), causing atypical pneumonia defined as coronavirus disease 2019 (COVID-19), was identified in China (17). It has rapidly expanded worldwide leading to a still ongoing global pandemic (https://www.who. $\mathrm{int} / \mathrm{dg} / \mathrm{speeches/detail/who-director-general-s-opening-}$ remarks-at-the-media-briefing-on-covid-19\%2D\%2D-11march-2020).

In order to reduce transmission rate, intensive care admissions and thus hospital bed saturation, in March 2020, the Italian Government imposed a strict lockdown extended to the whole country (https://www. gazzettaufficiale.it/eli/id/2020/03/11/20A01605/sg).

Everyday life was disrupted by introducing the so-called 'smart-working' for many workers and 'e-learning' for students, using digital platforms on electronic devices. Gatherings and any kind of outdoor sports activity were prohibited.

Since the beginning of March 2020, we have observed an increase in outpatient pediatric endocrinological consultations for suspected precocious or early puberty (EP). In a previous preliminary study, we reported a doubling of the consultations for suspected precocious puberty recorded in the outpatient clinic database of the Endocrinology Unit of Bambino Gesù Children's Hospital between March and September 2020, in comparison with the same period of 2019 ( 246 vs 118 patients, respectively), with a prevalent increase of girls (18).
No significant differences in the number of consultations were observed during the remaining months of 2020, compared to the corresponding months of 2019 (93 vs 78 subjects, respectively, $P=0.10$ ) (data not published).

A previous Italian study had reported an increased incidence of newly diagnosed central precocious puberty (CPP) and a faster pubertal progression during and after lockdown (19).

The time spent on electronic devices increased during lockdown, while daily physical activity decreased with a concomitant increase of sedentary behavior (20). Finally, an increase of stress-related symptoms has been observed in children and adolescents throughout the pandemic $(21,22)$.

This retrospective multicenter study aimed to confirm this phenomenon and provide a plausible explanation.

\section{Methods}

\section{Subjects}

The study involved 506 subjects observed in five Italian tertiary centers of Pediatric Endocrinology, in the periods March-September 2020 and March-September 2019 ('Bambino Gesù' Children's Hospital in Rome, IRCCS ‘Giannina Gaslini’ Hospital in Genoa, University Hospital 'Federico II' in Naples, Pediatric Hospital Microcitemico ‘Antonio Cao' in Cagliari, Pediatric Clinic of Perugia Hospital).

Data were collected retrospectively from the outpatient clinic database of each center. Girls younger than 3 years referred for idiopathic premature thelarche were not considered. Four patients affected by Silver Russell Syndrome were excluded due to their known susceptibility to develop precocious puberty, while 12 subjects were lost during follow-up. The study population (total $=490$ children) was divided into 2019 and 2020 groups and subsequently into different subgroups according to the final diagnosis: transient thelarche (TT), non-progressive precocious puberty (NPP), CPP, or EP, when pubertal signs started between 8 and 9 years in girls and between 9 and 10 years in boys. The study design is summarized in Fig. 1.

The Institutional Review Board of 'Bambino Gesù' Children's Hospital approved the study protocol.

\section{Data collection}

Age, sex, ethnicity, family history of precocious and EP, maternal age at menarche, history of adoption, mid-

This work is licensed under a Creative Commons Attribution-NonCommercial-NoDerivatives 4.0 International License ifica com at $04 / 26 / 2023$ 01:51:22PM 


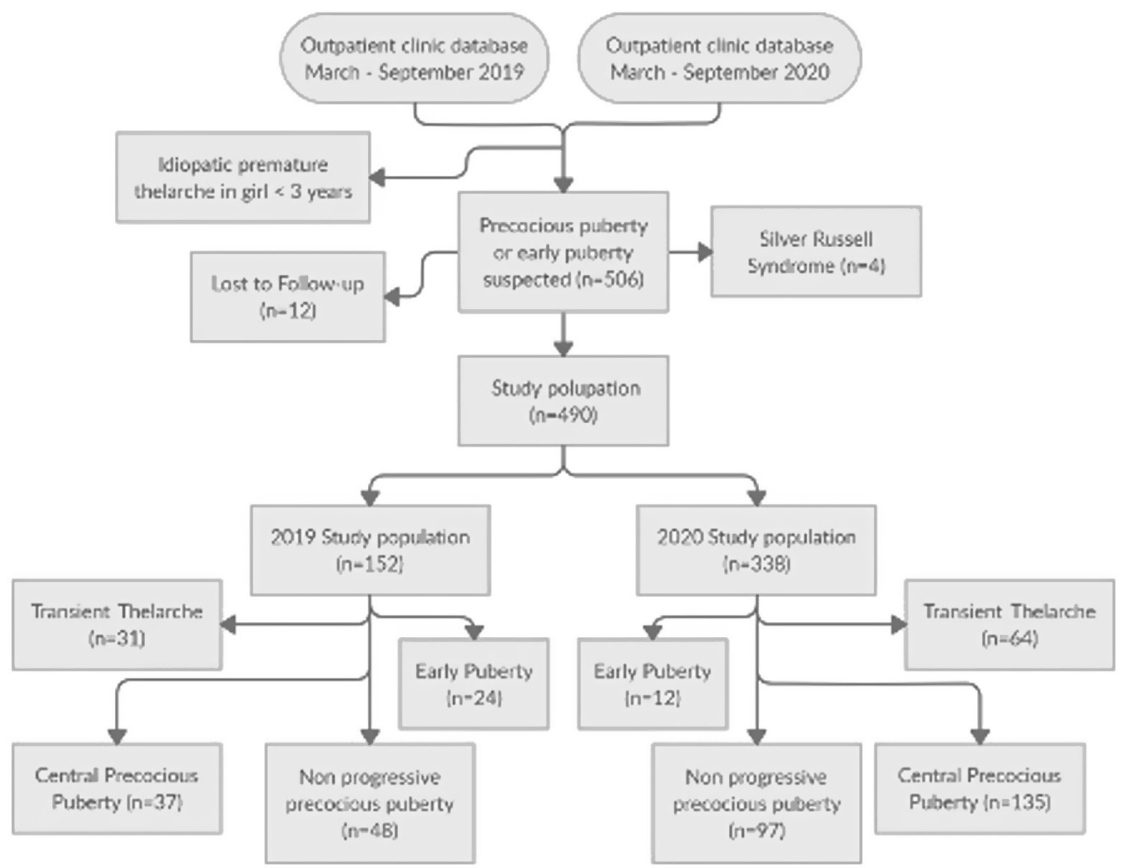

Figure 1

Flowchart summarizing the study design. parental height, age at the onset of pubertal signs, and age at the first observation were retrieved from clinical records. Height, weight, birth weight, and BMI were expressed as standard deviation score (SDS) according to the Italian standards (23). Pubertal stage was recorded according to Marshall and Tanner's genital stage (24), using Prader orchidometer for testicular volume (25).

The following hormone levels were recorded at baseline, when available: follicle-stimulating hormone (FSH), leuteinizing hormone (LH), estradiol, and testosterone. Gonadotropin-releasing hormone (GnRH) stimulation test was performed in 270 girls (64 in 2019 and 206 in 2020) and 15 boys (6 in 2019 and 9 in 2020), by the i.v. administration of GnRH (Lutrelef; Ferring) at a dosage of $100 \mu \mathrm{g}$, with FSH and LH measurement at $0,+30,+60$, and +90 min after the injection.

A detectable basal LH level (>0.2 IU/L) and/or a peak response of $\mathrm{LH}$ after $\mathrm{GnRH}$ infusion $>5 \mathrm{IU} / \mathrm{L}$, with or without serum estradiol levels $>20 \mathrm{pg} / \mathrm{mL}$, were considered suggestive of CPP $(16,26,27)$. In the absence of these biochemical parameters, subjects with slow pubertal progression were classified as NPP. Subjects presenting with thelarche that disappeared during the diagnostic workup were defined as affected by TT.

Peripheral precocious puberty due to non-classical congenital adrenal hyperplasia was excluded with basal and corticotropin-stimulated 17-OH-progesterone in patients presenting with pubarche and/or adrenarche in association with thelarche.

\section{Laboratory measurements}

Estradiol, LH, and FSH were measured by chemiluminescence immunoassay (ADVIA Centaur; Siemens). Estradiol intra- and inter-assay coefficients of variation were 3.1 and $6 \%$, respectively. The analytical measuring range for estradiol assay was 11.8 to 3000 $\mathrm{pg} / \mathrm{mL}$ (43.3-11.013 pmol/L). LH intra- and inter-assay variability coefficients were 2.2 and $4.4 \%$, respectively, with analytical measuring range 0.1-200.0 IU/L. FSH intra- and inter-assay variability coefficients were 2.2 and $3.7 \%$, respectively, with analytical measuring range $0.3-$ 200.0 IU/L. 17-OH-Progesterone was measured by RIA (ICN-Pharmaceutical Inc). Mean intra- and inter-assay coefficients of variation were 8.8 and $12 \%$, respectively. Testosterone was measured by chemiluminescence immunoassay (Centaur-Bayer provided by Siemens Medical Solutions Diagnostics), and intra- and inter-assay coefficients of variation were 3.8 and 5\%, respectively.

\section{Bone age assessment}

Bone age (BA), in years, was estimated from an x-ray of the left hand and wrist using the Greulich \& Pyle atlas (28) and revised by expert endocrinologists. Bone age advancement was defined as the difference between BA and chronological age expressed in years.

\section{Imaging}

Pelvic ultrasound was performed to assess uterine diameters and the endometrium pattern. A uterine longitudinal

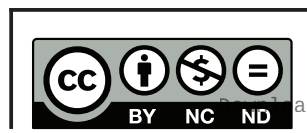

This work is licensed under a Creative Commons Attribution-NonCommercial-NoDerivatives 4.0 internationad dicense.ifica.com at 04/26/2023 01:51:22PM 
diameter $>34 \mathrm{~mm}$ was considered suggestive of estrogenic stimulation and incipient puberty. The majority of children in the CPP subgroups (22/37 in 2019 and 90/135 in 2020) underwent MRI of the hypothalamus-pituitary area (16).

\section{Questionnaires}

Lifestyle questionnaires investigating physical activity, eating habits, and electronic device use at the onset of pubertal signs were administered to both the 2020 and 2019 groups. The Italian version of the 'Physical Activity Questionnaire for Older Children' (29) was used for physical activity. A second questionnaire, analyzing the pandemic-related stress, was administered to 2020 group subjects.

\section{Statistical analysis}

Statistical analysis was performed using the SPSS Statistics software for Windows, version 22.0 (IBM Corp., Armonk, NY, USA). Continuous quantitative variables were expressed as mean \pm S.D., and categorical variables were expressed as frequency distribution, median, and interquartile range (IQR). Comparison of continuous variables was performed using the Student's $t$ test. Categorical variables were compared by the chi-square test, while differences in distributions of ordinal data from independent samples were tested with Mann-Whitney $U$ and Goodman and Kruskal's gamma tests. The level of significance was set at 0.05 (two-tailed).

\section{Results}

Between March and September 2020, 338 subjects were referred for suspected precocious puberty, compared to 152 subjects observed in the same period of $2019(+122 \%)$.

The prevalent increase was observed in girls (328 subjects in 2020 vs 140 subjects in $2019, P<0.05)$. In particular, the increase was more evident during the second part of the period considered; 236 girls were observed between June and September (72\%) and 92 girls between March and May (28\%).

No difference was observed in boys ( 10 subjects in 2020 vs 12 subjects in 2019). Based on these results, we decided to further analyze only the female population of each period.

Family history of precocious and EP was positive in $30 \%$ of the total female population, without differences between 2019 and 2020 (31 and 29\%, respectively). Eight girls had been adopted (four girls in 2019 and four girls in 2020), three of them belonged to the NPP subgroup and five to the CPP subgroup.

The percentage of girls with CPP was significantly higher in the 2020 group, compared to the 2019 group (135/328 vs $37 / 140$ girls, equivalent to $41 \%$ vs $26 \%$, $P<0.01$ ), while a relative reduction of EP was observed in 2020 compared to 2019 (10\% vs 17\% respectively, $P<0.01)$. The proportion of TT and NPP was similar between 2019 and 2020. A higher number of girls was diagnosed with CPP during the second part of the 2020 time interval, but the percentage of CPP cases out of the total number of girls observed was not different (101/236 girls between June and September (43\%) vs 37/92 girls between March and May (40\%), $P=0.67$ ).

The clinical characteristics of all the female subgroups are summarized in Table 1. Both 2019 and 2020 subgroups showed a trend toward a postnatal weight gain (defined as BMI SDS - birth weight SDS), without significant differences between 2019 and 2020 subgroups. The mean difference of the upward mismatch between birth weight and BMI SDS reached statistical significance in both 2019 CPP and EP subgroups $(P<0.05)$ and in 2020 CPP subgroup $(P<0.05)$ (Fig. 2).

Anthropometric parameters and biochemical findings were similar in CPP subgroups of 2019 and 2020. Only $16 \%$ of the MRI scans ( 7 cases in 2019 and 11 cases in 2020 subgroups) showed minor brain abnormalities, none of them related to organic CPP.

Anthropometric parameters were similar in 2019 and 2020 TT subgroups, except for a significantly lower BMI SDS in 2020 TT subjects $(-0.17 \pm 0.99$ vs $0.47 \pm 1.02$, respectively; $P<0.01$ )

Height SDS was significant different in the two NPP populations $(0.96 \pm 1.16$ in 2019 vs $0.54 \pm 1.13$ in 2020 , $P<0.05)$, while BMI SDS was not different $(0.31 \pm 1.10$ in 2019 vs $0.15 \pm 1.28$ in $2020 ; P=0.447$ ).

Both NPP and EP subgroups of 2020 were significantly younger at the time of the first consultation $(7.19 \pm 0.85$ years in $2020 \mathrm{NPP}$ vs $7.49 \pm 0.88$ in $2019 \mathrm{NPP}, P<0.05$; $8.64 \pm 0.44$ years in $2020 \mathrm{EP}$ vs $8.91 \pm 0.45$ in $2019 \mathrm{EP}$, $P<0.05)$. On the contrary, the age at the onset of pubertal signs was similar in 2019 and 2020 subgroups.

\section{Lifestyle questionnaires}

Lifestyle questionnaires were administered in order to compare the different populations (2019 vs 2020), as well as the subgroups of the same year (CPP vs TT, NPP, and EP patients). The same questionnaire was also used to analyze

This work is licensed under a Creative Commons Attribution-NonCommercial-NoDerivatives 4.0 International License ifica com at $04 / 26 / 2023$ 01:51:22PM 


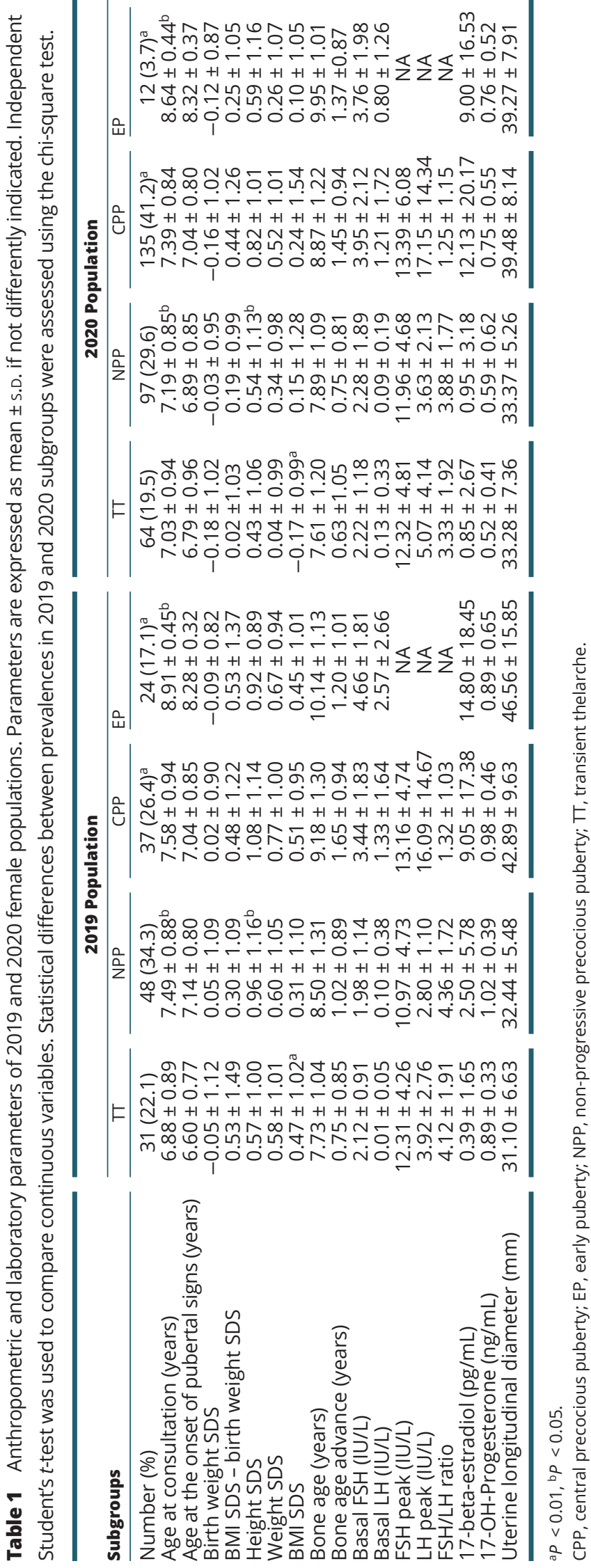

https://ec.bioscientifica.com https://doi.org/10.1530/EC-21-0650

2022 The authors Published by Bioscientifica Ltd lifestyle changes during the pandemic, compared to prepandemic habits, in the 2020 subgroups.

As expected, the overall time spent on electronic devices was greater in the 2020 group (median 5-10 h/week, IQR (1-5 to 10-15 h) in 2019 vs 15-20 h/week, IQR (5-10 to more than $25 \mathrm{~h}$ ) in 2020; $P<0.001$ ) (Fig. 3A), although no difference was observed among the different 2020 subgroups.

All the 2020 population attending primary school reported the introduction of 'e-learning' concurrently with the lockdown, with an increase of weekly device use for homework (median never, IQR (0) in 2019 vs $5-10 \mathrm{~h} /$ week, IQR (never to $>10 \mathrm{~h}$ ) in 2020; $P<0.001)$, without significant difference between the 2020 subgroups.

The same weekly time spent on electronic devices for leisure activities was reported in 2019 and 2020 groups (median 5-10 h/week, IQR (1-5 to >10 h) in 2019 vs $5-10 \mathrm{~h} /$ week, IQR (never to $>10 \mathrm{~h}$ ) in 2020; $P=0.24$ ).

The subgroup of 2020 CPP girls reported prolonged overall weekly use of electronic devices, already present before the pandemic, in comparison with the rest of the 2020 population (median $1-5 \mathrm{~h} /$ week, IQR (never to 5-10 h) in CPP vs $1-5 \mathrm{~h} /$ week, IQR (0) in other subgroups; $P<0.05)$ (Fig. 3B).

Physical activity (expressed as hours/week) was considerably lower in the 2020 group (median: no physical activity, IQR (never to $1-2 \mathrm{~h}$ /week) in 2020 vs median: 1-2 h/week, IQR (0) in 2019; $P<0.001$ ) (Fig. 4).

Weekly physical activity was significantly lower in 2020 CPP girls, compared to the other 2020 subgroups taken together (median never, IQR (0) in CPP vs never, IQR (never to $1-2 \mathrm{~h} /$ week) in other subgroups $P<0.05$ ) (Fig. $5 \mathrm{~A})$. The same result was evident comparing pre-pandemic habits of the 2020 CPP subgroup with pre-pandemic habits of the other 2020 subgroups (median 1-2 h/week, IQR (0) in CPP vs 1-2 h/week, IQR (never to 3-4 h/week) in other groups, $P<0.05$ ) (Fig. 5B).

Finally, $47 \%$ of the 2020 subjects reported a significant increase in the sense of hunger during the pandemic, compared to the previous year. Daily intake of leavened food was increased in $38 \%$ of the 2020 subjects, although no difference was evident between the 2020 CPP subgroup and the other 2020 subgroups taken together. No differences in the weekly intake of meat or junk food were reported between 2019 and 2020 groups.

The second questionnaire, analyzing the pandemicrelated stress in the 2020 group, showed that more than half of the 2020 subjects (59\%) reported behavioral changes and a relevant increase in stress-related symptoms
This work is licensed under a Creative Commons Attribution-NonCommercial-NoDerivatives 4.0 elnternationad dicense ifica. com at 04/26/2023 01:51:22PM 


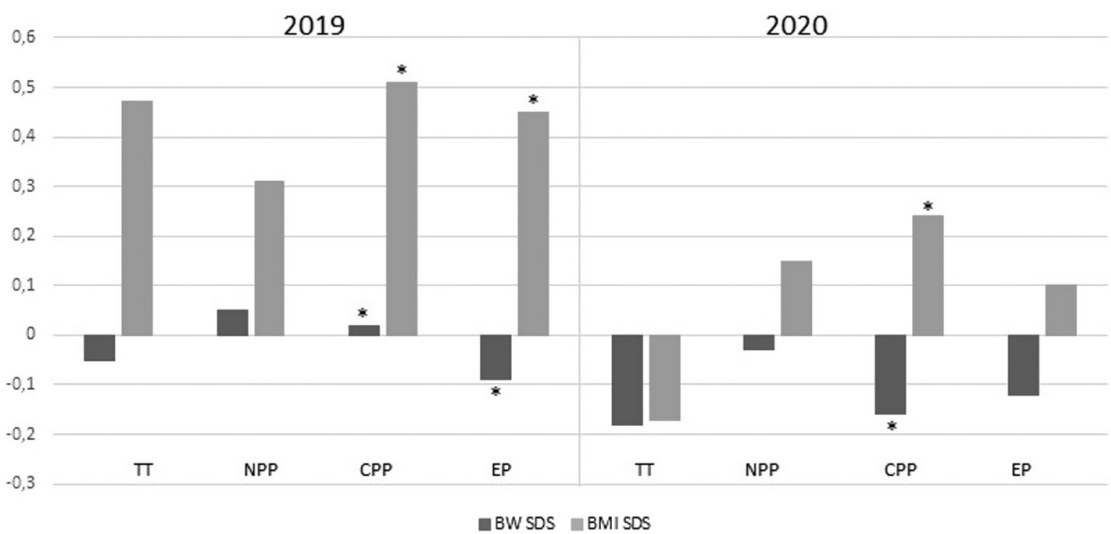

Figure 2

Upward mismatch between mean birth weight and BMI SDS in 2019 and 2020 subgroups (TT, transient thelarche; NPP, non-progressive precocious puberty; $\mathrm{CPP}$, central precocious puberty; EP, early puberty. * $P<0.05$ ).
(63\%), without any differences between CPP and the other subgroups.

\section{Discussion}

Our multicenter retrospective study revealed a relevant increase in the number of consultations for suspected precocious puberty in girls $(+122 \%)$ between March and September 2020 compared to the same period of 2019. In addition, the percentage of confirmed cases with true CPP

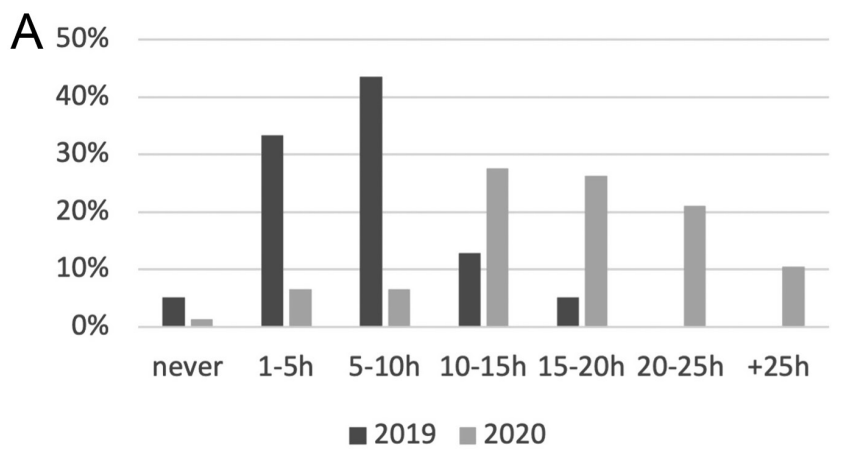

$\mathrm{B}$

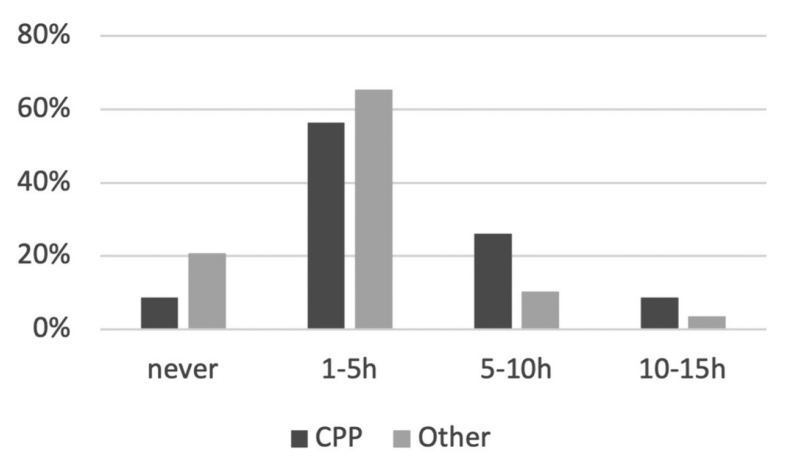

Figure 3

(A) Overall weekly use of electronic devices in 2019 and 2020 populations. (B) Pre-pandemic weekly use of electronic devices in 2020 subgroups (CPP, central precocious puberty; Other, transient thelarche, early puberty, and non-progressive precocious puberty subgroups). was significantly higher in the 2020 group compared to the 2019 group ( $41 \%$ vs $26 \%$, respectively).

Two previous studies reported an increase in the number of new cases of CPP in girls during the COVID-19 pandemic $(18,19)$. Furthermore, Stagi et al. (19) described a faster pubertal progression in patients already followed for slowly progressive CPP. The authors reported an increase of BMI after lockdown in these subjects, assuming a possible causal role of weight gain on pubertal progression.

Since 1970, it has been hypothesized that critical body weight and a critical level of adiposity may trigger pubertal development $(9,30,31,32,33)$. Leptin, secreted by adipocytes, acts as a permissive stimulus on GnRH pulsatile secretion $(33,34)$. On the contrary, adiponectin inhibits GnRH release resulting in a delayed onset of puberty. TNF- $\alpha$ and IL- 6 inhibit the production of adiponectin-stimulating puberty onset (35). Kisspeptins, released by hypothalamic kisspeptin neurons, have a stimulatory action on GnRH neurons and seem to be the gatekeepers of puberty onset (36). Recent studies demonstrated that childhood obesity causes EP onset by the activation of kisspeptin release and eventually GnRH pulsatile secretion, although specific changes induced by leptin on kisspeptin neurons are not fully understood (37). Finally, epigenetic factors such as sirtuins and ceramides have been implicated on the modulation of KISS1 transcription $(8,36,38)$.

In our study, BMI was not increased in 2020 patients compared to 2019 patients, with z-score BMI within +1 SDS in all 2019 and 2020 subgroups. Nevertheless, an upward mismatch was observed comparing mean birth weight and BMI SDS in both 2019 and 2020 CPP. This finding supports the proposed hypotheses that an early pubertal maturation in girls may represent an adaptive process to escape from ectopic adiposity in subjects with low birth weight and increased postnatal weight gain. In these subjects prenatal s.c. adipocyte development (adipogenesis) is impaired preventing the safe postnatal

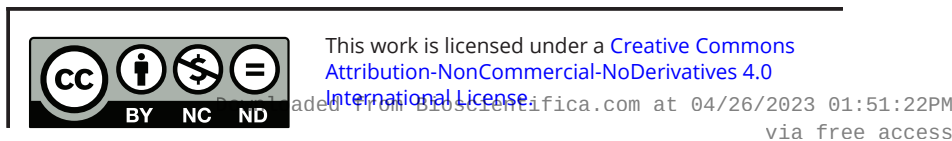




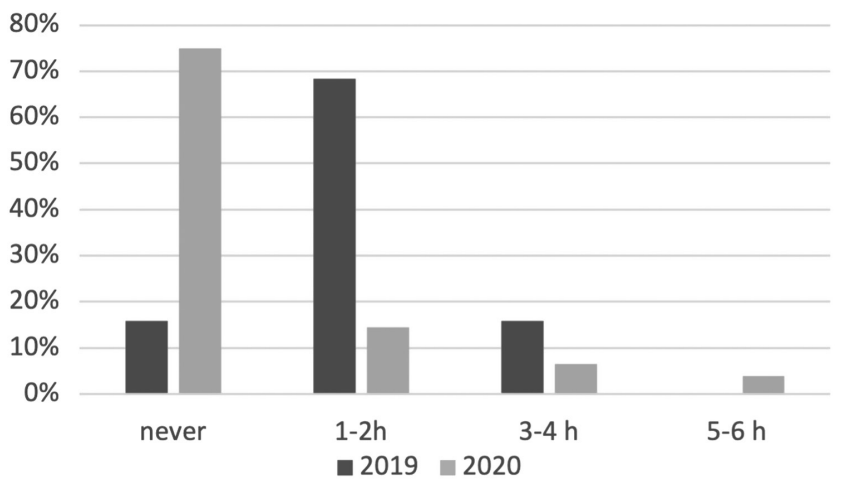

Figure 4

Overall weekly physical activity in 2019 and 2020 populations.

s.c. fat accumulation when an early and fast postnatal weight gain occurs $(12,13,14)$. Other authors have interpreted this mismatch as a consequence rather than a trigger of EP, as female puberty is characterized by an early change of body composition with body fat increase (15).

Physical activity was considerably lower or nearly absent in the 2020 group. Interestingly, 2020 CPP girls were more sedentary both before and during the pandemic compared to 2019 CPP subjects. Poor physical activity may have exerted a negative influence on body composition decreasing muscle mass and increasing ectopic fat deposition, without a clear BMI increase. Fat accumulation has been related to high inflammatory cytokine levels and low adiponectin levels leading to an early onset and fast progression of puberty (35).

While intense physical activity has been associated with delayed puberty, less data are available on the relationship between moderate physical activity or sedentary lifestyle and EP (39). Beyond purely physical exercise, several studies demonstrated a positive association between physical activity and psychological well-being in children and adolescents. On the other hand, a sedentary lifestyle was related to both increased depression and lower life satisfaction and happiness. It has been suggested that promoting physical activity and decreasing sedentary behavior might protect mental health in children and adolescents (40). Early studies $(41,42)$ suggested that psychological stress itself (due to insecure bonds with parents or parental conflicts) may modify pubertal timing. A recent study reported that anxiety and other internalizing symptoms in prepubertal girls are associated with early pubertal onset, independently from maternal anxiety, BMI, ethnicity, and maternal education (11).

A few recent studies $(43,44,45)$ investigated the impact of COVID-19 and quarantine on mental health of children and adolescents, reporting a significant increase in behavioral and emotional disorders as a consequence of school closures. Post-traumatic stress disorder has been described in $30 \%$ of children during quarantine or social isolation (45).

In our study more than half of the 2020 population reported behavioral changes and a relevant increase in stress-related symptoms. We could assume that a dysregulation of stress-induced brain neurotransmitters underlies the increase of new cases of precocious puberty in girls, related to the COVID-19 pandemic. Stress may act as a more powerful trigger on GnRH-secreting neurons in girls with additional risk factors as a sedentary lifestyle already evident before the pandemic.

We observed that the overall use of electronic devices was greater in 2020 than in 2019 population. The total weekly time spent using electronic devices was increased due to their use for 'e-learning' during the pandemic lockdown, with no concomitant decrease of daily screen time for leisure activities. Girls of the 2020 CPP group showed a more prolonged weekly use of electronic devices, already evident before the pandemic, compared to the rest of the 2020 population.

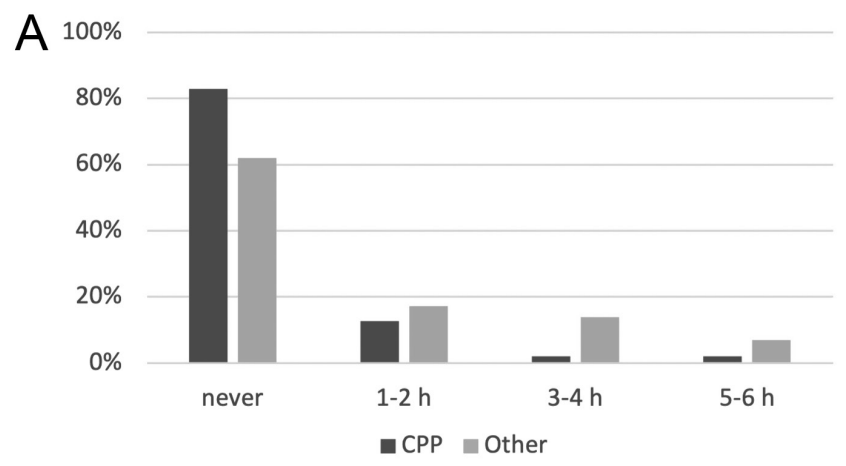

B

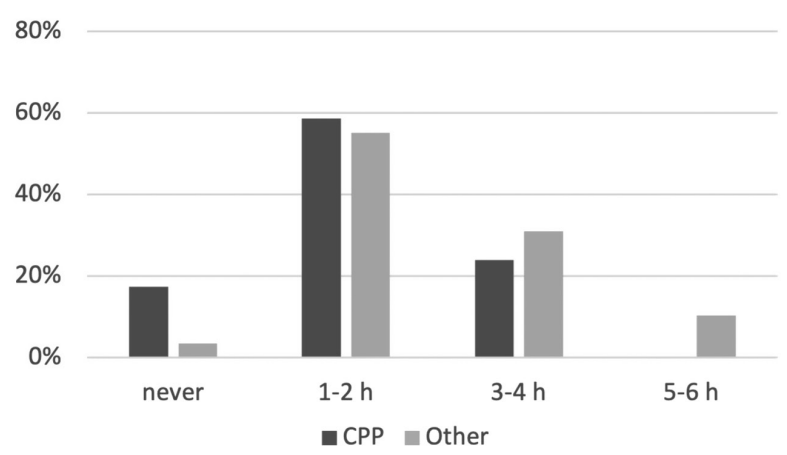

Figure 5

(A) Pandemic weekly physical activity in 2020 subgroups. (B) Prepandemic weekly physical activity in 2020 subgroups (CPP, central precocious puberty; Other, transient thelarche, early puberty, and non-progressive precocious puberty subgroups). 
Different studies hypothesized that the progressive reduction in the age of pubertal onset and the increased incidence of precocious puberty over the last 20 years can be related to environmental factors including chemicals that mimic hormonal action. The so-called endocrine disruptors may have estrogen activity or may cause an increase of endogenous estrogen secretion $(46,47,48)$. Flame retardants have been widely used in the last decades to reduce flammability of electronic devices. Their effect as endocrine disruptors interfering with pubertal development has been demonstrated in animal and human studies $(49,50,51)$.

A different exposure to endocrine disruptors during the pandemic is unprovable. On the other hand, endocrine disruptors exert their action after having slowly accumulated in the human body due to prolonged environmental exposure. Therefore, they are unlikely related to the rapid increase in the incidence of precocious puberty during the pandemic.

In our study, the increase of new cases of precocious puberty did not involve boys. Male precocious puberty is overall less common and it is more often the result of predisposing genetic mutations or organic disorders of the hypothalamic-pituitary axis. On the other hand, the impact of environmental triggers on pubertal timing in males is still not fully understood. The clarification of the reasons for this sexual dimorphism would require prolonged observation and a greater number of cases.

We are aware that the retrospective design of our study, together with the fact that living habits and physical activity were self-reported, represents clear limitations in the evaluations of the results. However, it was a multicenter study with relatively large sample size, and similar increases of precocious puberty were observed across the five Italian centers involved (located in different geographic regions).

To our knowledge, no previous studies have analyzed the impact of daily lifestyle changes on puberty. The sharp increase in cases of precocious puberty observed during the first COVID-19 pandemic wave suggests that rapid changes in physical activity, use of electronic devices, and pandemic-related stress may trigger the GnRH pulsatile secretion leading to puberty onset.

\section{Declarations of interest}

The authors declare that there is no conflict of interest that could be perceived as prejudicing the impartiality of the research reported.

\section{Funding}

This work did not receive any specific grant from any funding agency in the public, commercial or not-for-profit sector.

\section{Data availability}

The data that support the findings of this study are available on request from the corresponding author, C B.

\section{Author contribution statement}

All authors contributed to the study conception and design. Material preparation, data collection, and analysis were performed by $L C, C B, M V$, $D F, L P, C G, M S, D C$, and $N$ d I. The first draft of the manuscript was written by $L C$ and $C B$, all authors commented on previous versions of the manuscript. $M C, M M$, and $S \mathrm{~L}$ reviewed the manuscript. All authors read and approved the final manuscript.

\section{References}

1 Abreu AP \& Kaiser UB. Pubertal development and regulation. Lancet: Diabetes and Endocrinology 20164 254-264. (https://doi.org/10.1016/ S2213-8587(15)00418-0)

2 Beccuti G \& Ghizzoni L. Normal and abnormal puberty. In Endotext. Eds KR Feingold, B Anawalt, A Boyce, G Chrousos, WW de Herder, K Dhatariya, K Dungan, A Grossman, JM Hershman, J Hofland, et al. South Dartmouth (MA), 2000

3 Latronico AC, Brito VN \& Carel JC. Causes, diagnosis, and treatment of central precocious puberty. Lancet: Diabetes and Endocrinology 2016 4 265-274. (https://doi.org/10.1016/S2213-8587(15)00380-0)

4 Avendano MS, Vazquez MJ \& Tena-Sempere M. Disentangling puberty: novel neuroendocrine pathways and mechanisms for the control of mammalian puberty. Human Reproduction Update 201723 737-763. (https://doi.org/10.1093/humupd/dmx025)

5 Palmert MR \& Boepple PA. Variation in the timing of puberty: clinical spectrum and genetic investigation. Journal of Clinical Endocrinology and Metabolism 200186 2364-2368. (https://doi.org/10.1210/ jcem.86.6.7603)

6 Parent AS, Teilmann G, Juul A, Skakkebaek NE, Toppari J \& Bourguignon JP. The timing of normal puberty and the age limits of sexual precocity: variations around the world, secular trends, and changes after migration. Endocrine Reviews 200324 668-693. (https:// doi.org/10.1210/er.2002-0019)

7 Aksglaede L, Sorensen K, Petersen JH, Skakkebaek NE \& Juul A. Recent decline in age at breast development: the Copenhagen Puberty Study. Pediatrics 2009123 e932-e939. (https://doi.org/10.1542/peds.20082491)

8 Heras V, Castellano JM, Fernandois D, Velasco I, Rodriguez-Vazquez E, Roa J, Vazquez MJ, Ruiz-Pino F, Rubio M, Pineda R, et al. Central ceramide signaling mediates obesity-induced precocious puberty. Cell Metabolism 202032 951.e8-966.e8. (https://doi.org/10.1016/j. cmet.2020.10.001)

9 Brix N, Ernst A, Lauridsen LLB, Parner ET, Arah OA, Olsen J, Henriksen TB \& Ramlau-Hansena CH. Childhood overweight and obesity and timing of puberty in boys and girls: cohort and siblingmatched analyses. International Journal of Epidemiology 202049 834-844. (https://doi.org/10.1093/ije/dyaa056)

10 La Rocca C, Maranghi F, Tait S, Tassinari R, Baldi F, Bottaro G, Buzzigoli E, Carli F, Cianfarani S, Conte R, et al. The LIFE PERSUADED project approach on phthalates and bisphenol A biomonitoring in Italian mother-child pairs linking exposure and juvenile diseases. Environmental Science and Pollution Research International 201825 25618-25625. (https://doi.org/10.1007/s11356-018-2660-4)

11 Knight JA, Kehm RD, Schwartz L, Frost CJ, Chung WK, Colonna S, Keegan THM, Goldberg M, Houghton LC, Hanna D, et al. Prepubertal internalizing symptoms and timing of puberty onset in girls. American Journal of Epidemiology 2021190 431-438. (https://doi.org/10.1093/ aje/kwaa223)
This work is licensed under a Creative Commons Attribution-NonCommercial-NoDerivatives 4.0 elnternationad dicense.ifica . com at 04/26/2023 01:51:22PM 
12 de Zegher F, López-Bermejo A \& Ibáñez L. Central obesity, faster maturation, and 'PCOS' in girls. Trends in Endocrinology and Metabolism 201829 815-818. (https://doi.org/10.1016/j.tem.2018.09.005)

13 Harbulot C, Lessim S, Simon D, Martinerie L, Storey C, Ecosse E, De Roux N, Carel JC \& Léger J. Prevalence and clinical characteristics of isolated forms of central precocious puberty: a cohort study at a single academic center. European Journal of Endocrinology 2021 184 243-251. (https://doi.org/10.1530/EJE-20-0862)

14 de Zegher F \& Ibáňez L. On the rising incidence of early breast development: puberty as an adaptive escape from ectopic adiposity in mismatch girls. European Journal of Endocrinology 2021185 L1-L2. (https://doi.org/10.1530/EJE-21-0287)

15 Léger J, Delcour C, de Roux N \& Carel JC. Response to Letter to the Editor from de Zegher and Ibanes: on the rising incidence of early breast development. European Journal of Endocrinology 2021185 L3-L4. (https://doi.org/10.1530/EJE-21-0445)

16 Carel JC \& Leger J. Clinical practice. Precocious puberty. New England Journal of Medicine 2008358 2366-2377. (https://doi.org/10.1056/ NEJMcp0800459)

17 Wang C, Horby PW, Hayden FG \& Gao GF. A novel coronavirus outbreak of global health concern. Lancet 2020395 470-473. (https:// doi.org/10.1016/S0140-6736(20)30185-9)

18 Verzani M, Bizzarri C, Chioma L, Bottaro G, Pedicelli S \& Cappa M. Impact of COVID-19 pandemic lockdown on early onset of puberty: experience of an Italian tertiary center. Italian Journal of Pediatrics 2021 47 52. (https://doi.org/10.1186/s13052-021-01015-6)

19 Stagi S, De Masi S, Bencini E, Losi S, Paci S, Parpagnoli M, Ricci F, Ciofi D \& Azzari C. Increased incidence of precocious and accelerated puberty in females during and after the Italian lockdown for the coronavirus 2019 (COVID-19) pandemic. Italian Journal of Pediatrics 202046 165. (https://doi.org/10.1186/s13052-020-00931-3)

20 Stockwell S, Trott M, Tully M, Shin J, Barnett Y, Butler L, McDermott D, Schuch F \& Smith L. Changes in physical activity and sedentary behaviours from before to during the COVID-19 pandemic lockdown: a systematic review. BMJ Open Sport and Exercise Medicine 20217 e000960. (https://doi.org/10.1136/bmjsem-2020-000960)

21 Spinelli M, Lionetti F, Pastore M \& Fasolo M. Parents' stress and children's psychological problems in families facing the COVID-19 outbreak in Italy. Frontiers in Psychology 202011 1713. (https://doi. org/10.3389/fpsyg.2020.01713)

22 Loades ME, Chatburn E, Higson-Sweeney N, Reynolds S, Shafran R, Brigden A, Linney C, McManus MN, Borwick C \& Crawley E. Rapid systematic review: the impact of social isolation and loneliness on the mental health of children and adolescents in the context of COVID19. Journal of the American Academy of Child and Adolescent Psychiatry 202059 1218.e3-1239.e3. (https://doi.org/10.1016/j.jaac.2020.05.009)

23 Cacciari E, Milani S, Balsamo A, Spada E, Bona G, Cavallo L, Cerutti F, Gargantini L, Greggio N, Tonini G, et al. Italian cross-sectional growth charts for height, weight and BMI (2 to $20 \mathrm{yr}$ ). Journal of Endocrinological Investigation 200629 581-593. (https://doi. org/10.1007/BF03344156)

24 Tanner JM \& Whitehouse RH. Clinical longitudinal standards for height, weight, height velocity, weight velocity, and stages of puberty. Archives of Disease in Childhood 197651 170-179. (https://doi. org/10.1136/adc.51.3.170)

25 Zachmann M, Prader A, Kind HP, Hafliger H \& Budliger H. Testicular volume during adolescence. Cross-sectional and longitudinal studies. Helvetica Paediatrica Acta 197429 61-72.

26 Neely EK, Hintz RL, Wilson DM, Lee PA, Gautier T, Argente J $\&$ Stene M. Normal ranges for immunochemiluminometric gonadotropin assays. Journal of Pediatrics 1995127 40-46. (https://doi. org/10.1016/s0022-3476(95)70254-7)

27 Bangalore Krishna K, Fuqua JS, Rogol AD, Klein KO, Popovic J, Houk CP, Charmandari E, Lee PA, Freire AV, Ropelato MG, et al. Use of gonadotropin-releasing hormone analogs in children: update by an
International Consortium. Hormone Research in Paediatrics 201991 357-372. (https://doi.org/10.1159/000501336)

28 Greulich WW \& Pyle SI. Radiographic Atlas of Skeletal Development of Hand Wrist, 2nd ed. Stanford, CA: Stanford University Press, 1971.

29 Gobbi E, Elliot C, Varnier M \& Carraro A. Psychometric properties of the physical activity questionnaire for older children in Italy: testing the validity among a general and clinical pediatric population. PLoS ONE 201611 e0156354. (https://doi.org/10.1371/journal. pone.0156354)

30 Frisch RE \& Revelle R. Height and weight at menarche and a hypothesis of critical body weights and adolescent events. Science 1970 169 397-399. (https://doi.org/10.1126/science.169.3943.397)

31 Kaplowitz PB. Link between body fat and the timing of puberty. Pediatrics 2008121 (Supplement 3) S208-S217. (https://doi. org/10.1542/peds.2007-1813F)

32 Freedman DS, Khan LK, Serdula MK, Dietz WH, Srinivasan SR \& Berenson GS. Relation of age at menarche to race, time period, and anthropometric dimensions: the Bogalusa Heart Study. Pediatrics 2002 110 e43. (https://doi.org/10.1542/peds.110.4.e43)

33 Ahmed ML, Ong KK \& Dunger DB. Childhood obesity and the timing of puberty. Trends in Endocrinology and Metabolism 200920 237-242. (https://doi.org/10.1016/j.tem.2009.02.004)

34 Shalitin S \& Gat-Yablonski G. Associations of obesity with linear growth and puberty. Hormone Research in Paediatrics 2021 279-295. (https://doi.org/10.1159/000516171)

35 Nieuwenhuis D, Pujol-Gualdo N, Arnoldussen IAC \& Kiliaan AJ. Adipokines: a gear shift in puberty. Obesity Reviews 202021 e13005. (https://doi.org/10.1111/obr.13005)

36 Sanchez-Garrido MA \& Tena-Sempere M. Metabolic control of puberty: roles of leptin and kisspeptins. Hormones and Behavior 2013 64 187-194. (https://doi.org/10.1016/j.yhbeh.2013.01.014)

37 Navarro VM. Metabolic regulation of kisspeptin - the link between energy balance and reproduction. Nature Reviews: Endocrinology 2020 16 407-420. (https://doi.org/10.1038/s41574-020-0363-7)

38 Vazquez MJ, Velasco I \& Tena-Sempere M. Novel mechanisms for the metabolic control of puberty: implications for pubertal alterations in early-onset obesity and malnutrition. Journal of Endocrinology 2019 242 R51-R65. (https://doi.org/10.1530/JOE-19-0223)

39 Calthorpe L, Brage S \& Ong KK. Systematic review and meta-analysis of the association between childhood physical activity and age at menarche. Acta Paediatrica 2019108 1008-1015. (https://doi.org/10.1111/apa.14711)

40 Rodriguez-Ayllon M, Cadenas-Sanchez C, Estevez-Lopez F, Munoz NE, Mora-Gonzalez J, Migueles JH, Molina-Garcia P, Henriksson H, MenaMolina A, Martinez-Vizcaino V, et al. Role of physical activity and sedentary behavior in the mental health of preschoolers, children and adolescents: a systematic review and meta-analysis. Sports Medicine 201949 1383-1410. (https://doi.org/10.1007/s40279-019-01099-5)

41 Belsky J, Steinberg L \& Draper P. Childhood experience, interpersonal development, and reproductive strategy: and evolutionary theory of socialization. Child Development 199162 647-670. (https://doi. org/10.1111/j.1467-8624.1991.tb01558.x)

42 Wierson M, Long PJ \& Forehand RL. Toward a new understanding of early menarche: the role of environmental stress in pubertal timing. Adolescence 199328 913-924.

43 Singh S, Roy D, Sinha K, Parveen S, Sharma G \& Joshi G. Impact of COVID-19 and lockdown on mental health of children and adolescents: a narrative review with recommendations. Psychiatry Research 2020293 113429. (https://doi.org/10.1016/j. psychres.2020.113429)

44 Cianfarani S \& Pampanini V. The impact of stress on health in childhood and adolescence in the era of the COVID-19 pandemic. Hormone Research in Paediatrics 2021 345-349. (https://doi.org/10.1159/000517460)

45 Demaria F \& Vicari S. COVID-19 quarantine: psychological impact and support for children and parents. Italian Journal of Pediatrics 202147 58. (https://doi.org/10.1186/s13052-021-01005-8) https://ec.bioscientifica.com https://doi.org/10.1530/EC-21-0650 (c) 2022 The authors Published by Bioscientifica Ltd
This work is licensed under a Creative Commons Attribution-NonCommercial-NoDerivatives 4.0 International License.ifica com at 04/26/2023 01:51:22PM 
46 Fudvoye J, Lopez-Rodriguez D, Franssen D \& Parent AS Endocrine disrupters and possible contribution to pubertal changes. Best Practice and Research: Clinical Endocrinology and Metabolism 201933 101300. (https://doi.org/10.1016/j. beem.2019.101300)

47 Krstevska-Konstantinova M, Charlier C, Craen M, Du Caju M, Heinrichs C, de Beaufort C, Plomteux G \& Bourguignon JP. Sexual precocity after immigration from developing countries to Belgium: evidence of previous exposure to organochlorine pesticides. Human Reproduction 200116 1020-1026. (https://doi.org/10.1093/ humrep/16.5.1020)

48 Vasiliu O, Muttineni J \& Karmaus W. In utero exposure to organochlorines and age at menarche. Human Reproduction 200419 1506-1512. (https://doi.org/10.1093/humrep/deh292)
49 Lilienthal H, Hack A, Roth-Harer A, Grande SW \& Talsness CE. Effects of developmental exposure to 2,2,4,4,5-pentabromodiphenyl ether (PBDE-99) on sex steroids, sexual development, and sexually dimorphic behavior in rats. Environmental Health Perspectives 2006114 194-201. (https://doi.org/10.1289/ehp.8391)

50 Chen A, Chung E, DeFranco EA, Pinney SM \& Dietrich KN. Serum PBDEs and age at menarche in adolescent girls: analysis of the National Health and Nutrition Examination Survey 2003-2004. Environmental Research 2011 111 831-837. (https://doi.org/10.1016/j.envres.2011.05.016)

51 Deodati A, Sallemi A, Maranghi F, Germani D, Puglianiello A, Baldari F, Busani L, Mancini FR, Tassinari R, Mantovani A, et al. Serum levels of polybrominated diphenyl ethers in girls with premature thelarche. Hormone Research in Paediatrics 201686 233-239. (https://doi. org/10.1159/000444586)

Received in final form 30 December 2021

Accepted 14 January 2021

Accepted Manuscript published online 14 January 2021 (c) 2022 The authors Published by Bioscientifica Ltd
This work is licensed under a Creative Commons Attribution-NonCommercial-NoDerivatives 4.0 Internationad dicense ifica. com at 04/26/2023 01:51:22PM 